\title{
Mainstreaming HIVIAIDS in Gauteng urban municipalities: A bridge too far?
}

\section{Commonwealth Journal of Local Governance \\ Issue 7: November 2010}

http:/lepress.lib.uts.edu.au/ojs/index.php/cjlg

\section{Francis Kintu}

University of Pretoria

South Africa

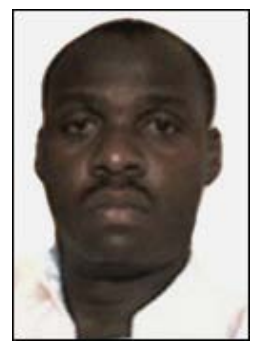

\section{Introduction}

Local government in South Africa, or 'developmental local government' as the lowest tier of government is often called (RSA 1998), carries the mandate of executing national development priorities of the country, as empowered by the constitution (RSA 1996), and by local government policy and legislation such as the White Paper on Local Government (RSA 1998) and the Municipal Systems Act (RSA 2000), that spell out the roles and responsibilities of local government. In terms of this mandate, local government is categorized into metropolitan, district and local municipalities, and has the responsibility of providing basic services such as water and sanitation, housing, and roads within those municipal jurisdictions, based on local integrated development plans (IDPs). ${ }^{1}$

The developmental role that has been assigned to local government becomes highly strategic in dealing with responses to HIV/AIDs. The National HIV/AIDS Strategic Plan 2007-2011 (RSA 2007) acknowledges the role of local governments in executing multi-sectoral

\footnotetext{
${ }^{1}$ Integrated development plans are comprehensive strategic and corporate plans formulated by municipalities in South Africa as the basis for their operations, for inter-government cooperation and for executing socio-economic development in communities. They are one of the core elements of a municipality's responsibilities, as legislated in the Municipal Systems Act, 2000.
} 
responses in communities by emphasizing the function of integrated development planning as an entry point to addressing HIV/AIDs.

The promulgation of the Framework for an integrated local government response to HIV/AIDS (DPLG 2005), developed as a support instrument to guide HIV/AIDS coordinators and IDP managers in municipalities on how to 'mainstream' the HIV/AIDs issue, has moved it to the centre stage of local government development and governance responses to HIV/AIDS in South Africa. Municipalities are gradually incorporating HIV/AIDS into their integrated development plans, with varying degrees of success depending on the availability of resources, levels of political support, the availability of planning expertise, and also the strength of partnerships between municipalities and civil society groups - community-based and non-government organisations.

As multi-sectoral efforts continue to be applied by local governments in urban areas in Africa and other countries as the optimum ways to deal with HIV/AIDS, more research input is needed to supplement existing information available to policy makers in various national governments on how to enhance approaches to HIV/AIDS multi-sectoral planning processes in various urban settings. It is in that context that this article seeks to add value to existing research.

This article discusses research about 'mainstreaming' HIV/AIDS in municipalities that was carried out in Gauteng province in 2009. It starts with a brief description of the background to the research in part two, and then proceeds with a conceptualization of mainstreaming HIV/AIDS at the local government level in part three. Part four presents the research methods used, and part five sets out the findings. Part six presents the main conclusions and recommendations.

\section{Background}

The research that informs this paper was carried out in the province of Gauteng, the smallest province by area in South Africa and the most urbanized, with $97 \%$ of its people living in urban areas. It is also the most heavily populated province, with a population of nearly 10.5 million people who account for $21.5 \%$ of the national total (Tomlinson 2007). The province 
is faced with the challenges of coping with high rates of in-migration from other parts of South Africa, leading to the proliferation of informal settlements (23\% of the population live in informal settlements), and the poor housing conditions associated with those settlements such as poor water supply and sanitation conditions, poor environmental health, poor nutrition etc. It is these conditions within the settlements that are the 'drivers' of the high HIV prevalence rate of 17.3\% (Tomlinson 2007; Van Donk 2007).

On a province by province basis, Gauteng currently has the second highest HIV antenatal prevalence (36\%) after Kwa Zulu Natal (ASSA 2008:3). In order to address the high prevalence of HIV, the province adopted a multisectoral HIV/AIDS strategy along with the establishment of a provincial Multisectoral AIDS Unit (MSAU) in 1998 to coordinate a provincial mainstreaming strategy. The MSAU coordinates the multi-sectoral Gauteng AIDs programme with a broad coalition of partners, ranging from provincial sector departments, to thirteen civil society partners (business sector, traditional healers, women's groups etc), and the metropolitan, district and local municipalities.

The Gauteng AIDs Plan 2009-2010 (Gauteng Multisectoral AIDS Unit 2009) which reflects the principles of the HIV/AIDS National Strategic AIDS Plan 2007-2011, envisages a central role for local government in the HIV/AIDS multi-sectoral response, in terms of coordinating prevention and care activities, working with civil society organizations, preparing workplace AIDS programmes, and the mainstreaming of AIDS responses into municipal services.

One of the key stipulations of the Plan charges local government departments with taking up the responsibility of mainstreaming HIV/AIDS in other sectors: “all government departments are required to address AIDS both internally, through workplace AIDS programmes and externally according to their core business in partnership with stakeholders from the relevant sectors” (Gauteng Multisectoral AIDs Unit, 2009:12).

\section{Conceptualizing mainstreaming HIVIAIDS at the local government level}

The United Nations philosophy behind mainstreaming HIV/AIDS in communities is based on addressing deprivations rooted in socio-economic imbalances that 'drive' the pandemic, such as poverty, gender inequality, the lack of adequate housing and sanitation, and food 
insecurity; whilst working with bio-medical interventions like prevention and care in order to create long lasting and sustainable responses (UNDP 2004; UNAIDS/GTZ 2002).

Multi-sectoral responses, or 'integrated responses', to HIV/AIDS interventions worldwide are proving to be a more effective way in dealing with susceptibility to HIV infection, as well as mitigating the burden of the disease on affected communities (UNAIDS/GTZ 2002). Mainstreaming HIV/AIDS at the local government level as a multi-sectoral response offers long lasting solutions to the pandemic, since it is able to address the factors that drive the pandemic within the broader community development context, or the 'social ecology' of HIV/AIDS (Van Donk 2007). According to UNAIDS (2002:10), mainstreaming HIV/AIDS is premised on six guiding principles. These include mainstreaming HIV/AIDS within existing institutional structures, distinguishing mainstreaming efforts as both internal and external domains, identifying 'entry points' in sectoral activities where HIV/AIDS can be targeted, and encouraging partnerships with civil society groups as well as community advocacy.

The central focus of mainstreaming HIV/AIDS in municipalities involves activities that ensure that HIV/AIDS becomes part of the core business of their functions, such as sector planning, budgeting, human resources policies, school curriculum, housing, roads, and water and sanitation. This process involves identifying entry points through which HIV/AIDS interventions can be integrated into municipal programmes without changing their core business (Elsey \& Kutengule 2003; UNDP UNAIDS \& World Bank 2005). Development programmes in municipal sectors such as housing, water and sanitation, roads etc. can be used to target both the social impacts of HIV/AIDS, as well as the 'environmental' factors that drive the epidemic. These efforts are known as 'external mainstreaming'. Internal mainstreaming on the other hand supports local government staff against the effects of HIV/AIDS. Effective mainstreaming means that all sectors in a municipality are able to successfully integrate HIV/AIDS into their day to day operations, giving consideration to: "how their day to day work contributes to vulnerability to HIV infection, and how their work impacts on people's ability to cope with HIV/AIDS” (HALOGEN 2009:5). Figure 1 below shows how HIV/AIDS is mainstreamed in municipal sectors: 


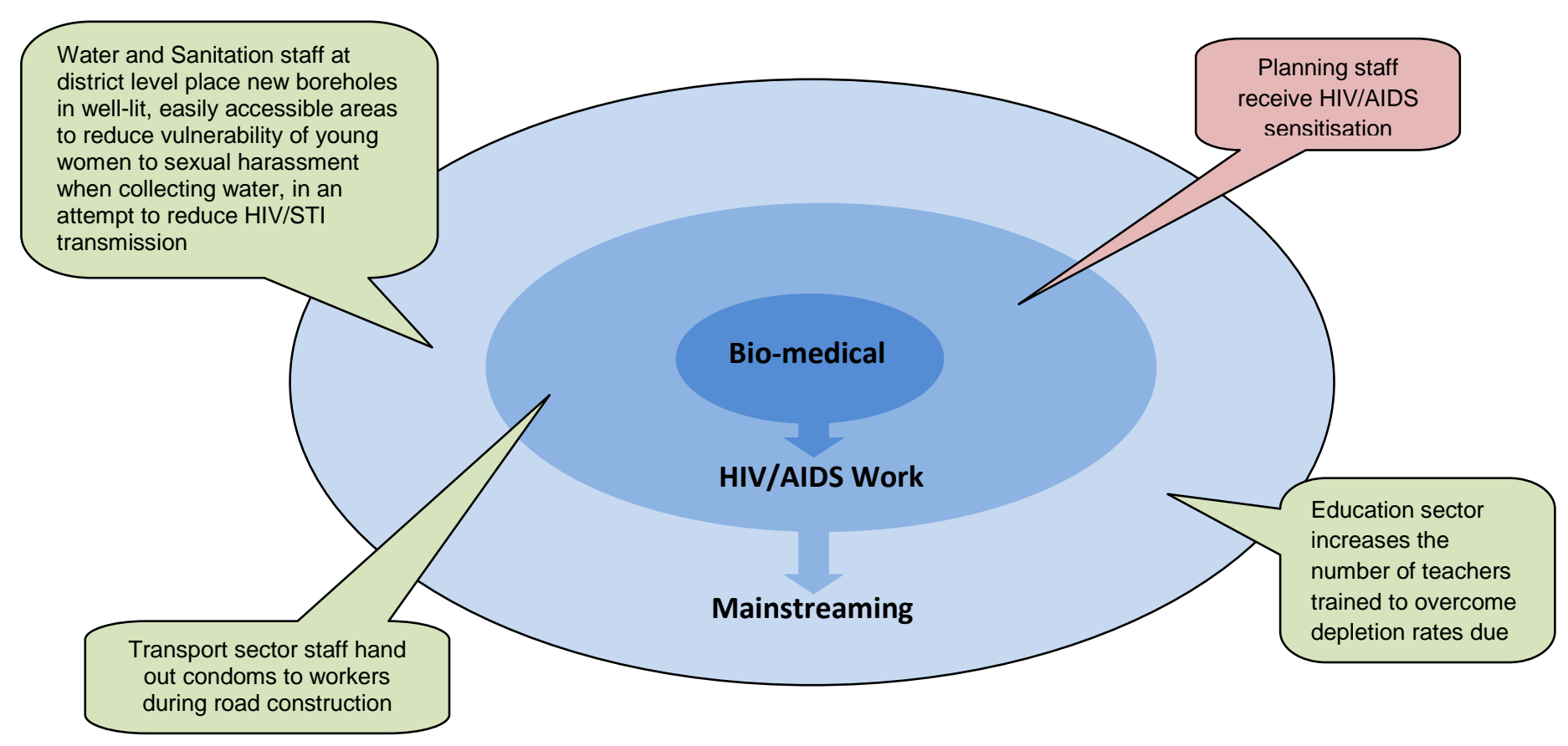

Figure 1: A conceptual model of HIVIAIDS mainstreaming at the municipal level (adapted from; Health Economics and HIVIAIDS Research Division, University of KwaZulu Natal 2003).

Key: Red - Internal: Staff and organisation issues - the sector as the employer; Green External: Service delivery work

These sector wide approaches to mainstreaming (SWAPs) are widely used in places with high HIV prevalence, and have proven to be successful in urban areas of countries such as Ghana and Uganda where local governments have used this approach to curb the spread of the pandemic (Elsey \& Kutengule 2003).

Despite the success of such programs, implementing sustainable mainstreamed HIV/AIDS responses through decentralized local government as the main delivery institution is also has challenges. Perhaps the greatest challenge is that of coordinating mainstreamed responses within the structure of multilevel governance and inter-governmental relations that demands joint operations by different spheres or levels of government, with their different responsibilities. Local governments must often grapple with a range of challenges:

- lack of clarity in the respective powers and functions of different tiers of government; 
- poor integration of vertically decentralized departments (particularly health departments) at the local level;

- poorly articulated frameworks for fiscal decentralization and unfunded mandates for local governments to respond to HIV/AIDS;

- problems in efficient management of inter-governmental transfers;

- lack of support for intergovernmental relations and co-ordinating structures;

- limited capacity of officials and councillors to manage the affairs of local government beyond delivering basic services (and specifically for planning and managing the new demands on local government as a consequence of HIV/AIDS); and

- lack of models for leading local government responses to HIV/AIDS (Kelly 2006:11).

\section{Research Methodology}

The research carried out in Gauteng province was exploratory in nature and aimed at drawing a comprehensive snapshot of how municipalities in the urban areas of Gauteng province are mainstreaming HIV/AIDS. It began with a desktop review of the integrated development plans of selected metropolitan, district and local municipalities to assess how municipalities integrated HIV/AIDS in those development plans. This was followed by semistructured interviews with municipal HIV/AIDS coordinators and integrated development planning managers in order to get first-hand information about approaches to HIV/AIDS mainstreaming, and thus to construct a consolidated report about the extent and nature of HIV/AIDS mainstreaming in the municipalities of Gauteng province.

\section{Results and discussion}

\section{Literature review}

An in-depth literature review of integrated development plans (IDPs) revealed that metropolitan municipalities had better responses to HIV/AIDS in terms of better strategic planning, well integrated sector plans, better inter-sectoral coordination, and better planned bio-medical (health based) responses. 
Planning for HIV/AIDS in district and local municipalities lacked substance, reflected in poorly integrated municipal sector plans, less articulation of HIV/AIDS plans in terms of deliverables or planned targets, and weak inter-sectoral coordination/integration for HIV/AIDS, as well as a marked preponderance of health based responses (e.g. curative, preventive care efforts etc.). The dominance of health based responses implies that these municipalities lacked the requisite capacity to manage mainstreamed responses. Mainstreaming was particularly absent in local municipalities, as opposed to district municipalities, suggesting that local municipalities on the whole lack the necessary skills needed to execute mainstreaming, or are disadvantaged in terms of their status as the lowest tier of government.

\section{Interviews with municipal officials}

The results from the interviews of municipality officials (HIV/AIDS coordinators and integrated development planning managers) corroborated the findings of the literature review. Metropolitan municipalities were clearly far ahead of district and local municipalities in all matters related to mainstreaming HIV/AIDS. Planning for HIV/AIDS was well orchestrated, in terms of involving other spheres (national, provincial) in their HIV/AIDS plans. Another distinguishing feature was that metropolitan municipalities had far less difficulty in integrating HIV/AIDS across municipal sectors, due to less internal bureaucratic resistance. One of the factors behind this well-coordinated HIV/AIDS mainstreaming was the level of political support behind the multi-sectoral strategy; in one metropolitan municipality, for example, the city's entire HIV/AIDS strategy was headed by the Executive Mayor, advised by the 'Metro Aids Council', responsible for strategic and operational planning of the HIV/AIDS multi-sectoral campaign in the city.

If the biggest weapon in the arsenal of the metro municipalities' HIV/AIDS multi-sectoral campaign was political support from the Mayor's office, then this was certainly the weakest link for district and local municipalities. Weak and largely uncoordinated HIV/AIDS mainstreamed responses that lacked both bite and substance were indicative of weak political support, and of the prevailing attitude that HIV/AIDS was primarily a health based issue. In most interviews respondents revealed that municipality officials failed to see HIV/AIDS as a 
developmental issue where socio-economic deprivations that 'drove' the pandemic needed to be given primary attention.

Given this attitude, it is hardly surprising that multi-sectoral responses had not yet taken root (especially in local municipalities) or were quite weak (in districts). District and local municipalities lacked the drive, initiative and organizational capabilities that metro municipalities exhibited; mainstreaming suffered from a 'triple whammy' of less than adequate planning, serious lack of resources, and most importantly, lack of inter-sectoral coordination or collaboration. Responding to HIV/AIDS was left to the social services and health sector. This problem affects areas with the highest HIV/AIDS prevalence rates in Gauteng province. In some municipalities mainstreaming was simply non-existent, yet these areas were in the direst need of implementing HIV/AIDS mainstreaming in order to break the stranglehold that the pandemic had put on the necks of urban communities.

The lack of partnerships between civil society and municipalities on one hand, and between spheres of government on the other, was another missing link that weakened HIV/AIDS mainstreaming. Successful mainstreaming operations at the municipal level require the full support and participation of civil community based and non-governmental organisations, but partnerships between these groups and municipalities were often either weak or simply nonexistent. Lack of sufficient vertical coordination between spheres of government resulted in irregular execution of HIV/AIDS efforts, inadequate resource allocation due to uncoordinated planning, and weak, uncoordinated HIV/AIDS efforts in municipalities. To date, the peculiar South African pseudo-federal structure of governance with its complex, top-down and bottom-up systems of inter-governmental planning has proven difficult to master; complications in inter-government coordination arising from this system are a major factor when it comes to mainstreaming HIV/AIDS (Van Donk 2008:2-4).

\section{Conclusion and Recommendations}

For most municipalities in Gauteng province, mainstreaming HIV/AIDS is a fairly new phenomenon in urban planning. It is not surprising therefore that the present pace of mainstreaming HIV/AIDS in Gauteng municipalities is slow and irregular, especially in district and local municipalities. Successful HIV/AIDS mainstreaming requires the optimal 
availability of human and non-human resources. Chief among these are sufficient skills and capacity in the municipality for strategic planning, financial planning and programme management skills, as well as the financial resources needed to bankroll multi-sectoral activities. There is also a need to optimize the functionality of inter-governmental planning and coordination, and legislation such as the groundbreaking Inter-governmental Relations Framework (2005) needs to be fully operationalised and implemented on the ground. This will greatly assist in realizing the effective joint planning and coordination between spheres that is essential in mainstreaming HIV/AIDS.

Nevertheless, municipalities can get still get it right provided:

- $\quad$ sufficient political support is available to drive HIV/AIDS multi-sectoral efforts;

- whether structures of governance such as partnerships between civil society and municipalities are robust enough; and

- whether sectors work together in municipalities to execute multi-sectoral HIV/AIDS responses.

One of the limitations of the research was an inability to focus sufficiently on these governance issues. Effective partnerships are one of the key determinants in successful HIV/AIDS multi-sectoral efforts, and further research is needed to better understand and evaluate their role in mainstreaming HIV/AIDS in the South African context. This will add more depth to the findings of this research in terms of understanding how best to implement sustainable and long lasting multi-sectoral responses to communities ravaged by HIV/AIDS in urban areas of South Africa.

\section{References}

Actuarial Society of South Africa (ASSA). 2008. Provincial Distribution of HIV/AIDs in South Africa, 2008.

Department of Local and Provincial Government. 2005. Framework for an integrated local government response to HIV/AIDS, Pretoria, Department of Provincial \& Local Government, South Africa.

Elsey, H., and Kutengule, P, 2003. HIV/AIDS Mainstreaming: A Definition, Some Experiences and Strategies, Durban, Health Economics and HIV/AIDS Research Division (HEARD), University of Kwa Zulu Natal \& Accra, Department for International Development, Ghana Office. 
Gauteng Provincial Government Multisectoral AIDS Unit, 2009 Gauteng Strategic Plan on AIDS for 2009/2010. Implementing the National Strategic Plan on HIV/AIDS for 2007 - 2011 in Gauteng Province.

HIV/AIDS Strategic Plan for South Africa. 2007-2011. <http://www.doh.gov.za/docs/misc/stratplanf.html>.

HALOGEN (HIV/AIDS and Local Government Learning Network) 2009. Municipal Brief 1, Mainstreaming HIV/AIDS into municipal IDPs.

Kelly, K. 2004. Supporting local government responses to HIV/AIDS: positions, priorities, possibilities, Centre for AIDS Development, Research and Evaluation (CADRE), Institute of Social and Economic Research, Rhodes University, South Africa.

Republic of South Africa. 1996. The Constitution of the Republic of South Africa, Act 108 of 1996.

Republic of South Africa. 2000. Municipal Systems Act 32 of 2000, Government Gazette no.21776, 20 November 2000, Pretoria, Government Printer.

Republic of South Africa. 1998. White Paper on Local Government. Government Gazette no. 18739, 13 March 1998, Pretoria, Government Printer.

Tomlinson, R. 2007. Impacts of HIV/AIDs at the Local Level. Report commissioned by the UN Management Programme of UN Habitat. $<$ http://web.wits.ac.za/NR/rdonlryes/Cities_in_a_world_of_cities.ppt $>$.

UNAIDS/GTZ. 2002. Mainstreaming HIV/AIDS, a conceptual framework and implementing principles, JSA Consultants Ltd \& GTZ Regional AIDS Programme Accra, Ghana.

UNDP, UNAIDS \& the World Bank. 2005. Mainstreaming HIV and AIDS in Sectors and Programmes, New York, UNDP.

Van Donk, M. 2007. City of Cape Town Multisectoral strategy, Cape Town, Isandla Institute.

Van Donk, M. 2008. The challenges and dilemmas of intergovernmental and intersectoral coordination, Input paper prepared for the Learning Event of the HIV/AIDS and Local Government Learning Network (HALOGEN). 